\title{
Expressões da violência por arma de fogo em crianças e adolescentes na região sul do Espírito Santo
}

\author{
Expressions of firearm violence to children and adolescents in the southern region of the \\ state of Espírito Santo
}

\section{Ana Paula Machado Ribeiro* Silvia Moreira Trugilho** Luciana Carrupt Machado Sogame ***}

Resumo: $O$ artigo aborda a violência por arma de fogo cometida contra crianças e adolescentes na região sul do estado do Espírito Santo, tendo por objetivo desenvolver uma análise crítica e reflexiva respeito das expressões dessa forma de violência. Resulta de uma pesquisa documental realizada a partir de dados extraídos de boletins unificados do Centro Integrado Operacional de Defesa Social (Ciodes) nos registros realizados no período de 2015 a 2017. Os resultados apontam índice crescente da violência por arma de fogo em municípios do sul do estado, incluindo pequenos municípios. Quanto às vítimas, os dados obtidos revelam que os adolescentes, em especial aqueles entre 16 e 17 anos, do sexo masculino, de cor parda e preta são as maiores vítimas da violência armada, com ferimentos na cabeça e tórax, tendo como elemento motivador o tráfico de drogas. Conclui-se que crianças e adolescentes encontram-se inseridos em processos sociais que potencializam a violência, na dinâmica desigual perversa que marca a sociedade brasileira, exacerbada pela sociabilidade do capital na sua atual organização produtiva e pela política neoliberal, em que o desmonte do Estado, a retração dos direitos sociais, a precarização do trabalho culmina na desproteção social de amplas parcelas da sociedade incluindo o segmento infanto-juvenil.

Palavras-chave: Violência. Arma de fogo. Criança e adolescente. Homicídio. Vulnerabildade.

Abstract: This article addresses firearm violence against children and adolescents in the southern region of the state of Espirito Santo in order to develop a critical and reflective analysis of the expressions of this form of violence. It results from a documentary research study carried out from data extracted from unified police reports of the Integrated Operational Center for Social Defense (Ciodes) in the records carried out from 2015 to 2017. The results show an increasing rate of firearm violence in municipalities in the south of the country, including small municipalities. As for the victims, the data obtained reveal that adolescents, especially those between 16 and 17 years old, male, brown and black, are the biggest victims of armed violence, with head and chest injuries, having as motivating element the drug trafficking. It is concluded that children and adolescents are inserted in social processes that maximize violence, in the perverse unequal dynamics that marks Brazilian society, exacerbated by the sociability of capital in its current productive organization and by neoliberal politics, in which the dismantling of the State, the retraction of social rights, the precariousness of work culminate in the social deprotection of large parts of society including the child and youth segment.

Keywords: Violence. Firearm. Child and adolescent. Homicide. Vulnerability.

\footnotetext{
* Mestre em Políticas Públicas e Desenvolvimento Local

** Doutora em Educação. Docente do Programa de Políticas Públicas e Desenvolvimento Local da Escola Superior de Ciências da Santa Casa de Misericórdia de Vitória - EMESCAM.

*** Doutora em Ciências da Saúde. Docente do Programa de Políticas Públicas e Desenvolvimento Local da Escola Superior de Ciências da Santa Casa de Misericórdia de Vitória - EMESCAM.
} 


\section{Introdução}

A violência sempre esteve presente na história da humanidade, mas o advento da racionalidade do capital em seu processo histórico de expansão e mundialização favoreceu a constituição de novas configurações de mundo e de sociabilidade que se projetam na realidade da vida social e como consequência vê-se erigir múltiplas formas de expressão da violência, materializadas cotidianamente no campo e nas cidades, como um fenômeno de natureza polissêmica, representativo das formas de manifestação da questão social.

No que se refere à violência por arma de fogo, a mesma se conforma como uma das maiores preocupações atuais da sociedade, despontando como alvo de inúmeros debates no âmbito público e privado. O número de homicídios por armas de fogo tem estado, já a algum tempo, entre as principais causas de mortes precoces no País, como bem demonstra Waiselfisz (2016).

No contexto atual da sociedade brasileira é imperativo discutir os efeitos negativos que conferem o uso de armas de fogo. Neste caso, destaque pode ser dado ao Projeto de Lei no 3.722/12, aprovado na Comissão Especial da Câmara dos Deputados (ainda pendente de aprovação no plenário), que regulamenta a licença para aquisição, posse e porte de arma de fogo (incluindo o direito de circular armado). Sua existência acentua o debate em torno da questão da violência armada, uma vez que está imbuído de revogar a legislação anterior em vigor - a Lei no 10.862/2003, conhecida como Estatuto do Desarmamento, que restringe o porte de armas no Brasil. Constitui-se, portanto, em uma verdadeira ofensiva contra o controle de armas no Brasil.

O texto propõe alterações em relação à idade mínima para aquisição e porte de arma de fogo, reduzindo de 25 para 21 anos, flexibiliza critérios para concessão e manutenção do porte, libera a propaganda em veículos de comunicação, aumenta a quantidade de armas e de munição a que cada pessoa tem direito, amplia o acesso a armas de uso restrito e grandes quantidades de munição para colecionadores, atiradores esportivos e caçadores, dentre outras alterações.

Trata-se de um projeto de lei que possui natureza conservadora e substancia o discurso de segurança da família e proteção da propriedade privada, contra o inimigo ameaçador; representado pelo "bandido" que ameaça o "cidadão de bem". Na prática, serve 
aos interesses da indústria bélica e da nossa elite patrimonialista conservadora, e não assegura a redução dos índices de violência. Ao contrário, algumas análises dão conta de que a liberação do acesso a armas e munição tende a aumentar a violência homicida, especialmente contra os mais jovens.

A crescente violência por armas de fogo, que já se verifica no país, traz consigo sentimento de insegurança, medo, revolta e injustiça, demandando a realização de estudos que possam contribuir para a elaboração de propostas de enfrentamento deste tipo de violência, convertido na contemporaneidade como um fenômeno social de grande magnitude, cujas consequências têm reverberado sobremaneira na sociedade brasileira.

Lopes, Costa e Musse (2018) destacam que, no Brasil, a mortalidade por causas externas da população infanto-juvenil resulta no maior número de Anos Potenciais de Vida Perdidos (APVP). Tal medida visa quantificar o número de mortes prematuras, ou seja, quando a morte acontece abaixo da faixa etária esperada, com isso os homicídios se tornam relevantes indicadores sociais, assim como de saúde pública.

Outro estudo, realizado por Freitas et al. (2017), conclui que no Brasil, além do elevado e crescente número de jovens vítimas fatais de arma de fogo, outros milhões são acometidos de lesões não fatais, que também incidem sobre os anos potenciais de vida perdidos. As estatísticas apontam que, para cada óbito de uma pessoa menor de 18 anos, outras 12 permanecem internadas ou acometidas de incapacidade permanente.

A realidade da violência por arma de fogo contra crianças e adolescentes evidencia a necessidade de refletir sobre as condições sociais de vida em que eles se encontram. Requer ainda pensar proposições para o seu enfrentamento não apenas sob a ótica da segurança pública, mas, sobretudo, da proteção social, de modo que o debate do tema favoreça o desenvolvimento e implementação de políticas públicas que possam assegurar a proteção social do segmento infanto-juvenil e a garantia dos direitos preconizados no Estatuto da Criança e do Adolescente (ECA).

Tendo em vista as considerações até aqui tecidas, objetivamos desenvolver uma análise crítica e reflexiva sobre as configurações da violência decorrente do uso de arma de fogo que vitima crianças e adolescentes. Para tanto, tomamos como referência as expressões dessa forma de violência presentes na realidade do sul do estado do Espírito Santo. Ao nosso ver, os dados levantados sobre tal realidade, mesmo em sua particularidade, servem como 
indicadores sociais para subsidiar a implementação de políticas públicas de proteção social para o segmento infanto-juvenil.

A partir de registros do Centro Integrado Operacional de Defesa Social (Ciodes) do sul do Espírito Santo, foi possível sistematizar informações relacionadas à violência por arma de fogo em crianças e adolescentes nessa região, destacando aspectos sociais relacionados às suas formas de expressão na realidade local. O Ciodes é um Órgão vinculado à Secretária Estadual de Segurança Pública (SESP), com a missão integrar e gerenciar agências de seguranças estaduais, federais e municipais para atendimento às ocorrências policiais.

No sul do estado, o Ciodes funciona sediado na cidade de Cachoeiro de Itapemirim desde 30 de março de 2010, sendo operacionalmente responsável pelo atendimento das ocorrências policiais das áreas do 9o Batalhão da Policia Militar, 9a CIA/IND, 10a CIA/IND. Os municípios incluídos nesses atendimentos são: Alfredo Chaves, Apiacá, Anchieta, Atílio Vivacqua, Cachoeiro de Itapemirim, Castelo, Iconha, Itapemirim, Marataízes, Mimoso do Sul, Muqui, Piúma, Presidente Kennedy, Rio Novo do Sul e Vargem Alta. Entretanto, quanto aos dados obtidos na pesquisa realizda, destacam-se os municípios de Atílio Vivacqua, Cachoeiro de Itapemirim, Marataízes, Piúma, Rio Novo do Sul e Vargem Alta.

O estudo foi desenvolvido fundamentado no referencial teórico-metodológico do materialismo histórico-dialético, pelo fato de ser um método que possibilita, por meio da indissociável relação entre teoria e método, a análise e compreensão da violência no âmbito da estrutura e totalidade social, no movimento contraditório de constituição de fenômenos sociais contextualizados e interconectados à totalidade dinâmica que é a realidade social e seus sistemas de mediações. Conhecer a violência na realidade social requer o conhecimento das suas múltiplas determinações e contradições inerentes ao movimento da realidade, por isso a fundamentação no método materialista histórico-dialético se justifica, pela consideração da violência como um fenômeno social que necessita ser problematizado criticamente no âmbito da sociedade capitalista e suas determinações.

Por meio de uma pesquisa documental, realizou-se coleta de dados em formulários do Ciodes, denominados de Boletim Unificado (BU), cujos registros relacionados à violência por arma de fogo envolvendo crianças e adolescentes compreenderam o período de 30 de março de 2010 a 31 de dezembro de 2017. No total, foram identificados 43 BUs, nos quais buscamos obter as seguintes informações: sexo, faixa etária, raça/cor, município de 
ocorrência, dados de morbimortalidade por arma de fogo, motivação da violência, circunstâncias em que ocorreu, formas de encaminhamento dado às vítimas. A concepção de crianças e adolescentes adotada encontra-se subsidiada no Art. 2 ㅇ da Lei $n$ ㅇ 8.069/90. Para efeitos dessa lei, considera-se criança a pessoa até 12 anos de idade incompletos e adolescente aquela entre doze e dezoito anos de idade (BRASIL, 1990).

O tratamento dos dados seguiu o método de análise de conteúdo, o que nos permitiu apontar aspectos qualitativos inerentes à expressão da violência por arma de fogo em crianças e adolescentes no sul do Espírito Santo. Procedemos à realização de uma análise interpretativa, realizando a mediação entre conteúdo, interpretação inferencial e o referencial teórico adotado a partir de levantamento bibliográfico realizado em bases de dados indexadas na área de ciências sociais aplicadas. Simultaneamente, realizamos uma descritiva analítica dos dados objetivos que representam elementos numéricos dessa forma de violência.

\section{Reflexões sobre a violência}

À medida que nos debruçamos sobre o estudo da violência é possível observar sua vinculação a outros temas correlatos, demandando ser compreendida em sua dimensão complexa, na medida em que constitui como parte de uma totalidade social, resultante de um conjunto de determinantes inseridos nos marcos históricos das relações de produção e na organização estrutural da sociedade, especialmente marcadas nas condições desiguais de poder e riqueza.

Transformações societárias contemporâneas decorrentes da expansão do capital em âmbito mundial e suas crises econômicas têm marcado contundentemente as relações sociais e instituído novos padrões de sociabilidade, com destaque para uma forma de sociabilidade fundada em valores preconceituosos, de intolerância e individualismo, que contribui sobremaneira para a exacerbação da violência na sociedade atual.

No Brasil, a violência tem relação íntima com a formação de nossa sociedade, fundada na desigualdade de poder e de acesso aos bens sociais historicamente existente entre as elites dominantes e as camadas populares. Assim, concordamos com a assertiva de Cadermatori e Roso (2012, p. 398) de que "[...] a violência esteve e está presente em nosso país, qualquer que seja a época histórica considerada, e embora tenha determinadas 
continuidades, a violência contemporânea tem peculiaridades de cunho mais estrutural $[\ldots] "$.

Nesta linha de raciocínio, Silva (2015) alerta que a explicação da violência está contida nos processos sociais que a produzem e reproduzem, que criam e recriam condições objetivas e subjetivas para sua materialidade a partir de condições sociais e históricas. Assim, a violência se move em um dinâmico e complexo processo social e se impõe como um grande desafio para a vida social e as políticas públicas na contemporaneidade.

As variadas formas de violência vivenciadas atualmente na cidade e no campo, dirigidas aos diferentes segmentos populacionais, de característica estruturante, se constituem em uma das faces da barbárie. Netto (2012), ao tratar da barbárie contemporânea a associa ao capitalismo em seu atual estágio de desenvolvimento, apontando a questão do belicismo como uma de suas faces e chama atenção para a "militarização da vida privada" (NETTO, 2012, p. 218).

A venda de armas e munições como fonte de negócio que sustenta o capital em tempo de crise, assinalada como "[...] grande negócio privado [...]" (NETTO, 2012, p. 218), repercute na questão das mortes violentas verificadas em nosso país, revelando-se como manifestação civilizatória do capital na contemporaneidade. A violência por arma de fogo, situada nas formas atuais de sociabilidade produzida e reproduzida nos processos e relações sociais e presentes no contexto de vida contemporâneo, incide, sobretudo, nas pessoas pertencentes aos segmentos sociais empobrecidas, moradores de áreas precarizadas das periferias urbanas, inscrita nas manifestações civilizatórias do capital.

A abordagem da violência não pode ignorar o debate sobre questão social, dado que as expressões contemporâneas de violências se configuram como manifestações da questão social no atual estágio de desenvolvimento da sociedade capitalista. Assim, a violência letal que reduz a vida de milhares de pessoas, incluindo crianças, adolescentes e jovens no Brasil, merece ser compreendida inserida no debate sobre desigualdade e questão social.

As desigualdades sociais despontam como importante elemento analítico para se problematizar os crescentes índices de mortalidade por violência, com maior prevalência para o público jovem (que engloba adolescentes), principalmente os que se encontram nos segmentos menos favorecidos socialmente, que sucumbem ao predatório sistema de produção capitalista - uma realidade que, com os fetichismos do capital, tende a potencializar 
o envolvimento de adolescentes e jovens em atividades ilícitas, na oportunidade idealizada de ascensão social, colocando-os mais vulneráveis a situações de riscos (HERNANDES, 2016).

Segundo Machado (2017), no ano de 2017 o Brasil apresentou uma média de 30 assassinatos por dia de jovens e crianças, sendo a maioria negros e pobres, colocando o País em segundo lugar na lista de países que concentram a maioria dos crimes contra pessoas com idade até 19 anos; já o Espírito Santo registrou, no ano de 2015, o percentual de 27,6\% homicídios contra menores de 19 anos - acima da média nacional de 20,7\%.

A violência causada por armas de fogo só não é considerada um escândalo no País porque as vítimas, em sua maioria, são jovens, pobres e negros, como alude Nery (2005). Nessa linha de raciocínio, Figueiredo et al. (2017) referem que o preconceito, o racismo e as desigualdades sociais presentes na sociedade brasileira revelam-se como principais dispositivos para o aumento da violência que atinge o público infanto-juvenil.

Neste contexto, mostra-se preocupante a situação de exposição à violência por arma de fogo em que se encontram crianças e adolescentes, em especial aquelas de cor preta ou parda, de camadas pobres da sociedade brasileira, incluindo a realidade do Espírito Santo. É ainda preocupante o atual cenário que aponta o risco da facilitação de acesso à arma de fogo, tomada como objeto de desejo para uma suposta "proteção à vida".

\section{Arma de fogo: mercado, fetiche e política pública}

Netto (2012) apresenta duas importantes contribuições para refletirmos sobre a questão do acesso e porte de armas, permitindo a compreensão de sua representação como fetiche e como sustentação do mercado para o capital em tempos de crise. Na concepção do autor, a sociedade capitalista tardo-burguesa contempla a cultura do consumo em uma vida social mercantilizada. Neste aspecto, a arma de fogo assegura manutenção da economia sob a ordem do capital, na medida em que se insere no processo de "[...] estruturação fetichista da mercadoria e do tardo-capitalismo" (NETTO, 2012, p. 212).

Destaque pode ser dado a outra importante contribuição das ideias do autor, a partir do argumento de que as atividades econômicas da indústria bélica no século XX representaram um importante mecanismo para a auto reprodução do capitalismo em suas crises, assentando o belicismo como um grande negócio capitalista na atualidade. Por 
conseguinte, tal fato permite a emergência da militarização da vida social - um aspecto da realidade social que contribui, sobremaneira, para a comercialização de armas de fogo e sua circulação na sociedade; tanto quanto o comércio clandestino do tráfico favorece sua entrada na sociedade (NETTO, 2012).

A violência por arma de fogo e seu controle tem sido objeto de debate nas esferas social, econômica e política. Carvalho e Espíndula (2016) referem que o discurso do medo ante à violência se mostra presente na vida, tanto de moradores das áreas urbanas centrais e periféricas, quanto das áreas rurais. Para essa situação em muito contribui a circulação das armas de fogo na nossa sociedade. Portanto, o debate sobre a violência por elas perpetrada exige a consideração dos fatores que contribuem para o acesso à arma de fogo e sua representação como objeto de consumo e porte (legal ou não).

Ribeiro, Souza e Sousa (2017) afirmam ser a arma de fogo o instrumento mais utilizado para a prática de atos de violência e homicídios em países da América Latina. Assim, considerando o alto grau de letalidade da arma de fogo nas práticas de violência, discutir a respeito dos elementos que favorecem sua comercialização e utilização pode ajudar a afirmar ações que fortaleçam a política de desarmamento.

Quando atentamos para a questão do acesso e porte (que inclui manuseio e uso) de arma de fogo, é necessário compreender seu significado como objeto de desejo e, portanto, entendê-la como elemento de fetiche. Para Fontenelle (2006), a vida social mercantilizada e de cultura de consumo - produto do atual estágio de desenvolvimento do capitalismo -, atua para a intensificação do fetiche da mercadoria e do consumo presentes na vida social contemporânea, especialmente estimulados pela indústria de propaganda, que opera no sentido de incitar, na ação de consumo, a objetivação alienada das relações de produção. Assim, a arma de fogo (uma mercadoria) acaba se tornando objeto de fetiche (algo a ser cultuado) pelo poder que lhe é atribuído.

Silva (2013) afirma que a adolescência está situada em um momento marcado pela valorização cada vez maior do capital, do dinheiro e dos prazeres e poderes que ele oferece às pessoas, bem como à busca por realização de fetiches pessoais, aquisição de bens materiais e conquista de poder. Na interface com essa ideia, Freitas (2002) assinala que os adolescentes são facilmente capturados pelo poder da mídia propagandista, no que ela associa o consumo de mercadorias a fantasias de felicidade e sucesso. Por essa razão, para o autor, adolescentes 
cooptados pelo tráfico de drogas são suscetíveis ao fetiche relacionado à arma de fogo, pelo fascínio que ela exerce associado à sensação de ser alguém forte, destemido, poderoso.

Não obstante, o fetiche relacionado à arma de fogo, que conduz à idealização do seu porte e manuseio, atinge não somente adolescentes, mas pessoas em diversas faixas etárias e de ambos os sexos, por estar a arma associada à sensação de poder - um objeto ao qual se atribui um poder sobrenatural. Para Moura (2019), ao carregar uma arma o homem pode se sentir completo, forte e confiante para cometer a violência.

O comércio legal e o ilegal de armas de fogo constituem-se faces da mesma moeda, haja vista que sua produção e circulação no mercado favorece o aquecimento da economia em termos de crise, como já destacado anteriormente a partir das análises de Netto (2012). Embora se verifique nos discursos dos defensores da segurança pública militarizada uma culpabilização do comércio ilegal de armas e o tráfico de drogas como únicos responsáveis pelos altos índices de violência e morte por armas de fogo, cumpre também apontar o papel da militarização da segurança pública nesse nexo causal. Afinal, a militarização da vida social cumpre o papel ideológico de mascarar o interesse capitalista bélico, inscrito nos mercados internacional e nacional de armas.

Nesse sentido, a violência por arma de fogo e seu incremento na realidade brasileira atual se mostra um grande desafio para as políticas públicas. Seu enfrentamento requer ações integradas entre as diversas políticas sociais e a ação do Estado, mas não de um Estado repressivo e punitivo, e sim de um Estado protetor e democrático, que assegure a ampla defesa dos direitos humanos e sociais. A proposta de militarização da política de segurança pública representa a "[...] legitimação da defesa de políticas públicas de caráter neoconservador [...] (FREIRE; MURAD; SILVA, 2019, p. 214), tanto quanto contribui para a criminalização da pobreza, ao considerar os pobres como os protagonistas da violência e da criminalidade (CADERMATORI; ROSO, 2012).

Souza (2006) enfatiza que as decisões e análises sobre políticas públicas em relação à violência por arma de fogo em crianças e adolescentes implicam em responder questões como: quem ganha, o quê, por quê e que diferença faz; embora outras definições enfatizem o papel da política pública na solução dos problemas da violência. Muitos são os espaços que precisam ser engajados para a garantia dos direitos de proteção à infância e juventude, com a devida articulação entre eles para que possa ir além de meras proposições. 
Ressalta-se como importante para o enfretamento da violência, a efetividade das ações de proteção de crianças e adolescentes na garantia de direitos, o que demanda "[...] realizar uma articulação lógica intersetorial, interinstitucional, intersecretarial e, por vezes, intermunicipal [...]" (BAPTISTA 2012, p. 188). A garantia de direitos de crianças e adolescentes, dentro do campo geral das políticas públicas, pode ser reforçado por seu papel no conjunto de ações estratégicas. Há, portanto, que se discutir e constituir medidas de Segurança Pública, acompanhadas de outras políticas públicas, voltadas para o combate da realidade social em que o Brasil está imerso (NERY, 2005).

A disposição legal do Estatuto do Desarmamento - Lei no 10.826/2003, posteriormente regulamentada pelo Decreto $n^{\circ} 5.123 / 04$, buscava contribuir para resultados positivos quanto à redução de homicídios praticados por armas de fogo, por meio de propostas de aperfeiçoamento do modelo legal de regulação de armas e munições estabelecendo frentes de atuação para o enfrentamento do problema da violência.

O Estatuto do Desarmamento produziu avanços significativos em relação à legislação anterior, quanto à aquisição, porte e comércio de armas e munições, ao criar inúmeros embaraços e dificuldades ao seu acesso pelos cidadãos comuns, tendo por objetivo o desarmamento total da população civil (NERY, 2005). A revogação deste Estatuto por meio do Projeto de Lei 3.722/12 (BRASIL, 2012), representa um grande retrocesso no combate à violência por arma de fogo, na medida em que permite a facilidade de acesso à posse e ao porte de armas e munição.

\section{Espelho da violência por arma de fogo em crianças e adolescentes no sul do Espírito Santo}

Os dados obtidos por meio dos registros do Ciodes revelam características importantes da violência por armas de fogo em crianças e adolescentes, na região sul do estado do Espírito Santo. Sendo a violência por arma de fogo um grave problema que afeta diversos espaços constitutivos da sociedade, seu enfrentamento requer a implementação de ações efetivas a fim de combatê-la, em especial pela via das políticas públicas com ações intersetoriais voltadas para geração de emprego e renda, educação, cultura, habitação, transporte, saúde e melhoria das condições de vida dos segmentos populacionais mais vulneráveis. 
Por conseguinte, inúmeros têm sido os direcionamentos de segmentos da sociedade brasileira para a manutenção de pautas armamentistas em torno da flexibilização das exigências para acesso, posse e porte de armas. Dos projetos aprovados que promovem alteração no Estatuto do Desarmamento consta a permissão de moradores do campo usarem armas em toda a extensão da propriedade rural e não apenas na sede, além da redução da idade mínima de 25 para 21 anos para a compre de armas de fogo, também por moradores de áreas rurais.

Diante do contexto de inflexões no enfrentamento e controle da violência presente na sociedade brasileira, o Atlas da violência 2019 revela que o acesso facilitado às armas de fogo é altamente favorável ao incremento da violência uma vez que possui efeito sobre a violência letal e outros tipos de crime (IPEA, 2019). As diversas edições do Atlas da Violência têm mostrado um crescimento das taxas de homicídios nos últimos 25 anos no Brasil, acompanhado, paralela e concomitantemente, do aumento do uso de armas de fogo nas mãos da população. Para Minayo $(2006$, p. 40) “[...] o comércio de armas de fogo é o segundo mercado mais lucrativo do mundo, depois do petróleo".

Em um estudo sobre homicídios de jovens no Espírito Santo, Calazans, Trugilho e Sogame (2020), apontam em sequência histórica os dados relacionados a mortes de jovens, com índices sempre acima da média nacional. No sul do Espírito Santo, os dados que expressam a violência por arma de fogo em crianças e adolescentes, a partir dos registros existentes nos Boletins Unificados do Ciodes, revelam-se preocupantes no que diz respeito à idade, sexo, cor de pele, morbimortalidade, motivo da violência, o que se expõe na sequência.

Entre os anos analisados, que compreende o período de 30 de março de 2010 a 31 de dezembro de 2017, os números da violência por arma de fogo apresentam variação oscilante e curva ascendente em 2016 e 2017. Assim, verifica-se que o uso de armas de fogo tem sido uma constante na realidade social, resultando em mortes de pessoas pertencentes aos diferentes segmentos sociais, incluindo crianças e adolescentes. A distribuição numérica dos registros do Ciodes Sul no período estudado está representada na Tabela 1 disposta abaixo.

TABELA 1 - Distribuição dos registros de violência por arma de fogo em crianças e adolescentes no período de março 2010 a dezembro 2017 


\begin{tabular}{cc}
\hline Ano & $\mathbf{N}^{\circ}$ de casos \\
\hline 2010 & 4 \\
2011 & 6 \\
2012 & 7 \\
2013 & 4 \\
2014 & 2 \\
2015 & 4 \\
2016 & 8 \\
2017 & 8 \\
Total & 43 \\
\hline
\end{tabular}

Fonte: autoria própria, a partir dos dados do Ciodes Sul.

Nos anos analisados, a distribuição do número de casos de violência por arma de fogo em crianças e adolescentes nas cidades do sul do Espírito Santo, registrados pelo Ciodes Sul, apresentou uma variação oscilante até o ano de 2015 e de modo ascendente nos dois últimos anos, o que consideramos preocupante, pela crescente expressão dos números. Dados do Sistema de Informação sobre Mortalidade (SIM) do Ministério da Saúde, e de estudos existentes sobre a violência, apontam que no Brasil o público infanto-juvenil se torna cada vez mais a principal vítima de mortes por armas de fogo, e as estatísticas apontam que entre três mortes duas são de causas violentas (WAISELFISZ, 2016).

Em relação à distribuição dos casos de violência por arma de fogo em crianças e adolescentes entre os municípios, a Tabela 2, descortina sua ocorrência.

Tabela 2- Casos registrados na distribuição por municípios

\begin{tabular}{ccccccccccc}
\hline Município & \multicolumn{10}{c}{ Ano } \\
\cline { 2 - 10 } & $\mathbf{2 0 1 0}$ & $\mathbf{2 0 1 1}$ & $\mathbf{2 0 1 2}$ & $\mathbf{2 0 1 3}$ & $\mathbf{2 0 1 4}$ & $\mathbf{2 0 1 5}$ & $\mathbf{2 0 1 6}$ & $\mathbf{2 0 1 7}$ & Total \\
Atílio Vivacqua & 1 & 1 & - & - & - & - & - & - & $\mathbf{2}$ \\
$\begin{array}{c}\text { Cachoeiro de } \\
\text { Itapemirim }\end{array}$ & 2 & 4 & 4 & 4 & 1 & 2 & 7 & 5 & $\mathbf{2 9}$ \\
Marataízes & 1 & 1 & - & - & 1 & - & - & 1 & 4 \\
Piúma & - & - & - & - & - & 2 & 1 & 1 & 4 \\
Rio Novo do Sul & - & - & 2 & - & - & - & - & 1 & 3 \\
\hline Vargem alta & - & - & 1 & - & - & - & - & - & 1 \\
\hline
\end{tabular}

Fonte: autoria própria a partir dos dados do Ciodes Sul.

Dos 15 municípios atendidos pelo Ciodes no sul do estado do Espírito Santo, a violência por arma de fogo em crianças e adolescentes, no período adotado para este estudo, foi verificada em 6 deles, o que representa quase a metade dos municípios. Notadamente o 
município de Cachoeiro de Itapemirim aparece com 29 registros (de um total de 43) - uma quantidade de casos expressiva em relação aos demais municípios, inclusive nos dois últimos anos.

Pode-se compreender que Cachoeiro de Itapemirim, por ser a maior cidade do sul do estado e com maior população, expresse a realidade dos centros urbanos em relação à violência. No entanto, municípios menores como Marataízes e Piúma, cidades litorâneas e de pequeno porte, revelam que a violência não se restringe a aglomerados urbanos. A considerar ainda a realidade de Piúma, verifica-se que até o ano de 2014 não havia registros de casos de violência por arma de fogo em crianças e adolescente, passando a existir a partir de 2015, com a manutenção dessa realidade nos anos subsequentes.

A violência por arma de fogo mostrou-se mais contundentemente direcionada à faixa etária da adolescência. Em crianças verificou-se 1 único registro no período estudado, relacionado a uma criança de oito anos de idade, do sexo masculino, em 2016, no município de Cachoeiro de Itapemirim. O maior índice de violência por arma de fogo - 42 registros incidiu sobre a faixa etária adolescente, especialmente entre aqueles com idade entre 16 e 17 anos, conforme apresentado na tabela 3. Considerando o somatório das idades de 16 e 17 anos (ambas com maior número de registros) chega-se a 34 casos registrados, de um total de 43 BUs examinados. Este dado revela que a faixa etária do final da adolescência encontra-se muito vulnerável à violência por arma de fogo, o que repercute nas estatísticas oficiais de homicídios de jovens no Brasil.

Tabela 3 - Distribuição de casos de violência por arma de fogo em adolescentes

\begin{tabular}{cccccccccc}
\hline \multirow{2}{*}{ Faixa etária } & \multicolumn{10}{c}{ Ano } \\
\cline { 2 - 12 } & $\mathbf{2 0 1 0}$ & $\mathbf{2 0 1 1}$ & $\mathbf{2 0 1 2}$ & $\mathbf{2 0 1 3}$ & $\mathbf{2 0 1 4}$ & $\mathbf{2 0 1 5}$ & $\mathbf{2 0 1 6}$ & $\mathbf{2 0 1 7}$ & Total \\
13 & 1 & - & - & - & - & - & - & - & $\mathbf{1}$ \\
14 & - & 1 & 1 & - & - & 1 & - & 1 & 4 \\
15 & - & 1 & 1 & 1 & - & - & - & - & 3 \\
16 & - & 1 & 2 & 2 & 1 & 1 & 3 & 5 & 15 \\
17 & 3 & 3 & 3 & 1 & 1 & 2 & 4 & 2 & 19 \\
\hline
\end{tabular}

Fonte: autoria própria, a partir dos dados do Ciodes Sul.

A realidade contemporânea relacionada à condição de vida de jovens (categoria que inclui parcela de faixa etária adolescente) comporta diversos fatores relacionados à precarização da vida, desigualdade, pobreza, estigmatização, estruturando um fenômeno que 
Valenzuela (2016) denomina de juvenicídio, por resultar em uma condição persistente de alto índice de mortalidade de jovens, especialmente no contexto do México e América Latina, compondo um fenômeno exponencial de homicídios de jovens.

Trata-se, segundo esse autor, de um processo centrado na estratificação social e nas relações de subalternização que, por meio das diversas formas de precarização das condições de existência humana e violações de direitos, desestabiliza a vida dos jovens, subtrai as opções disponíveis para a efetivação de seus projetos de vida e amplia suas condições de vulnerabilidade econômica e social, resultando em uma dinâmica de criminalização e homicídio de significativa parcelas das juventudes (VALENZUELA, 2016).

E, neste caso, evidencia um processo social perverso, acentuadamente presente na realidade brasileira marcada pelo desenvolvimento capitalista tardio e periférico, intensificado pela dinâmica societária contemporânea decorrente do processo expansionista do capitalismo (SCHERER; NUNES, 2018). Com isso, pode-se apontar como o grande responsável pelo juvenicídio a dinâmica atual do capital no contexto de ascensão do projeto neoliberal, que desmonta o Estado social, acarreta a retração dos direitos sociais, produz marginalização e fortalece o Estado penal. Desse modo "[...] promove um processo de aniquilação da vida dos jovens, em especial dos jovens pobres e negros, em função dos interesses de manutenção das taxas de apropriação de riqueza [...]" (CALAZANS; TRUGILHO; SOGAME, 2020, p. 88).

Quando se atenta para a violência por arma de fogo em crianças e adolescentes em relação ao sexo e cor da pele, os dados obtidos na pesquisa, dispostos no Quadro 1, evidenciam as significativas diferenças existentes entre essas características das vítimas.

Quadro 1- Distribuição de casos de violência por arma de fogo por sexo e cor da pele

\begin{tabular}{|c|c|c|c|c|c|c|c|c|c|c|c|c|c|c|c|c|}
\hline Ano & \multicolumn{2}{|c|}{2010} & \multicolumn{2}{|c|}{2011} & \multicolumn{2}{|c|}{2012} & \multicolumn{2}{|c|}{2013} & \multicolumn{2}{|c|}{2014} & \multicolumn{2}{|c|}{2015} & \multicolumn{2}{|c|}{2016} & \multicolumn{2}{|c|}{2017} \\
\hline $\begin{array}{l}\text { Sexo } \\
\text { Cor da } \\
\text { Pele }\end{array}$ & 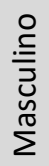 & 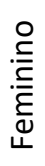 & 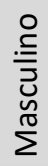 & 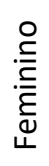 & 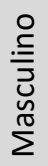 & 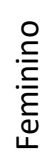 & 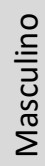 & 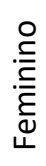 & 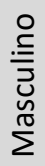 & . & 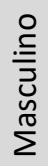 & 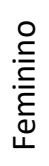 & 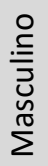 & 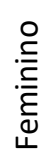 & 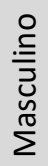 & 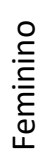 \\
\hline Branca & - & - & - & - & 1 & - & 1 & - & - & - & - & - & - & - & 1 & - \\
\hline Parda & 4 & - & 1 & - & 5 & 1 & 2 & - & 1 & - & - & - & 4 & - & 5 & - \\
\hline Preta & - & - & 3 & 2 & - & - & - & - & 1 & - & 1 & - & 4 & - & 2 & - \\
\hline $\mathrm{NI} *$ & - & - & - & - & - & & 1 & - & - & - & 3 & - & - & - & - & - \\
\hline
\end{tabular}

Fonte: autoria própria, a partir dos dados do Ciodes Sul. *Não informado. 
$\mathrm{Na}$ comparação entre os sexos, os dados obtidos revelam que o masculino apresentou índice elevado de violência por arma de fogo, observando-se a expressão de 40 vítimas, num total de 43 registros no período analisado. Esse achado apresenta conformidade com o que se encontra disposto em documentos como Atlas da Violência e Mapa da Violência. Segundo dados do IPEA (2019) há uma ocorrência de 55,0\% de homicídios de homens jovens (entre 15 e 29 anos) na comparação com o índice em mulheres que é de 41,7. Não obstante, embora haja uma disparidade de números entre os sexos, importa aqui ressaltar a preocupação com a condição da mulher nas situações de violência de gênero, considerando os aspectos de misoginia ainda presentes na sociedade brasileira, um componente adicional no problema da violência dirigida às juventudes.

$\mathrm{Na}$ análise da cor da pele, os dados obtidos revelam superioridade da violência por arma de fogo em adolescentes de cor parda e preta, com respectivamente 23 e 13 registros, na correlação com adolescentes de cor branca, apresentando apenas 3 casos. Fica claro, portanto, a disparidade da exposição à violência em relação à cor de pele; o que no Brasil não se desvincula da condição de classe social, e expressa a violência racista presente em nossa sociedade. O racismo estrutural tem sido determinante para a violência, o que é bem exposto pelos índices de mortalidade na realidade brasileira, configurando um genocídio da juventude negra periférica, conforme aponta Cardoso (2018).

Conhecer as causas e motivos geradores da violência contra crianças e adolescentes se mostra importante e necessário para a formulação de estratégias de combate à violência e seus determinantes sociais, econômicos, culturais, bem como a implementação de políticas públicas que materializem direitos de cidadania deste segmento populacional e possam contribuir para a redução das desigualdades sociais existentes em nosso País.

A violência é um assunto complexo e demanda esforços coletivos e articulados para sua superação. Entendida também como um fenômeno estruturante, mas que apresenta particularidades, buscamos conhecer motivos que acarretaram a violência por arma de fogo nos casos registrados pelos BUs analisados. Neste caso, foi possível identificar como principal elemento o tráfico de drogas.

A realidade nacional tem mostrado que é crescente o envolvimento de adolescentes e jovens no tráfico de drogas e na criminalidade dele decorrente. Tal fato contribui para que 
o jovem pobre, negro, expropriado dos meios de produção e cooptado pela economia ilegal do tráfico de drogas apareça como a grande expressão estatística da violência por arma de fogo. E, segundo Portella et al. (2019) o aumento do número de homicídio é visível em cidades com maior inserção do tráfico de drogas.

Faria e Barros (2011) referem que os jovens são cada vez mais precocemente aliciados pela economia ilegal do tráfico de drogas, dadas as condições de precarização de vida em que se encontram e as limitadas opções de escolha de outros modos de vida. Neste aspecto, o tráfico de drogas desponta como mercado lucrativo e opção de inserção para jovens moradores de áreas precarizadas, marcadas pela degradação das formas de trabalho e ausência de políticas públicas, como bem assinalam Scherer e Nunes (2018). O resultado se evidencia no processo de criminalização e morte de adolescentes revelando o juvenicídio presente na realidade estudada.

No que se refere ao local de ferimento, ficou evidenciado que as regiões do corpo atingidas por projéteis de arma de fogo (PAF) foram o tórax, a cabeça e as costas. Essa informação reflete a intencionalidade da autoria em relação a provocar morte ou grave ferimento nas vítimas. É preocupante constatar que os ferimentos provocados por arma de fogo em crianças e adolescentes, segundo o que demonstram os dados coletados nos BUs do Ciodes Sul não são superficiais, não intencionais; ao contrário, são provocados com a firme intenção de provocar a morte. Revelam, ainda, a intenção de eliminação pela morte, especialmente de adolescentes do sexo masculino, de cor parda e preta, ao que Boschetti (2017, p. 66) nos ajuda a decifrar como “[...] crescentes expressões da violência no campo e na cidade contra a juventude negra [...]".

Machado (2017) destaca que o alto índice de assassinato de crianças e jovens no Brasil posiciona o País em segundo lugar na relação daqueles em que se verifica o cometimento de crimes contra pessoas com idade até 19 anos. Também Waiselfisz (2016) aponta que o maior número de mortes por arma de fogo no Brasil contempla o público infanto-juvenil. Os dados obtidos junto aos BUs do Ciodes Sul a respeito da vitimização de crianças e, sobretudo, adolescentes pela violência por arma de fogo reafirmam essa realidade. $E$, desta forma, revelam a situação de vulnerabilidade e desproteção social em que estão colocadas crianças e jovens no Brasil diante da condição de precarização da vida, 
discriminação, estratificação social, violações de direitos produzidos pelo contexto econômico-social que culmina no juvenicídio.

Aponta-se ainda como condição de vulnerabilidade social e econômica que expõe crianças e adolescentes às mais variadas formas de violência, a inserção precoce em relações de exploração de trabalho e na economia ilegal do tráfico de drogas (FONSECA et al., 2013). A ocorrência de mortes de adolescentes por arma de fogo na associação com o tráfico de drogas nos leva a refletir a respeito da condição de vida de grande parcela de jovens no Brasil, na vulnerabilidade em que se encontram, inseridos perversamente nas condições desiguais de vida e, segundo Silva (2006), "[...] inseridos em processos sociais reconstituídos sob dadas condições históricas que potencializam a ação violenta [...]".

No que tange à condição de autoria da violência, essa questão se mostra extremamente preocupante pelo fato de evocar clamor social pela redução da maioridade penal. É importante ressaltar que este tema merece um amplo debate social que atente para as condições de vida em que se encontra grande parcela do segmento infanto-juvenil em nosso País: condição de vida adversa social e economicamente - marcada pelas contradições de classes - e as formas de sociabilidade contemporâneas a que se referem Gentilli e Trugilho (2014), o que acaba conduzindo adolescentes e jovens para a prática de atos violentos e a criminalidade.

Compreendemos, que, para o segmento infanto-juvenil pertencente às classes de mais baixa renda, os processos de violência aliados às múltiplas expressões da questão social que vivenciam tornam "[...] ainda mais complexa e avassaladora as consequências da subalternização de classe, plena de episódios de pura barbárie" (GENTILLI; TRUGILHO, 2014, p. 532).

O fenômeno da violência tem sua intensificação condicionada à dinâmica destrutiva do capital em seu atual estágio de desenvolvimento e sociabilidades decorrentes. Por meio das proposições perversas da política neoliberal, vem-se realizando cotidianamente a acentuação das desigualdades e precarização das condições de vida de amplas parcelas da sociedade por meio da precarização do trabalho, redução de direitos, desmonte o Estado e das políticas públicas. Imersos nessa realidade, crianças e adolescentes brasileiros, em significativo número, vivem expostos à violência cotidiana - uma das manifestações das 
relações sociais vulnerabilizadas e de sociabilidade exaurida -, efeito da dinâmica expansionista do capital.

Construir caminhos para o enfrentamento dessa realidade requer o desenvolvimento de ações dirigidas ao fortalecimento dos direitos sociais e à efetivação de políticas públicas fundamentadas na ética da proteção social como direito. Neste caso, a direção aponta para a perspectiva da intersetorialidade com vistas à realização de ações articuladas de educação, assistência social, cultura, saúde, entre outras, para o enfrentamento da violência cotidiana a que estão sujeitos crianças e adolescentes na realidade brasileira. 0 enfrentamento à violência envolve, pois, trabalho em vários eixos da esfera pública. Mas requer, sobretudo, a compreensão da dinâmica atual do sistema capitalista com seu padrão civilizatório destrutivo, por meio de uma análise crítica que subsidie a realização de ações efetivas na construção de uma nova ordem societária, mais humana e socialmente justa.

\section{Considerações finais}

Diante da realidade social contemporânea e dos modos de sociabilidade constituídas nos marcos da expansão globalizada do capital, o fenômeno da violência por arma de fogo que vitima crianças e adolescentes no País se espelha também no sul do estado do Espírito Santo, revelando condições de vulnerabilidade social deste segmento populacional, em especial os adolescentes negros e pobres, marcados pelas contradições de classes e injustiças sociais a que estão submetidos.

Expressa nas suas diversas formas, a violência nos convida a refletir sobre as contradições existentes na ordem social ditada pelos interesses do capital, que a cria e recria, imputando-nos desafios diários para sua erradicação em nossa realidade social. São muitos os desafios que a violência nos impõe para a condução de processos sociais que contribuam para a efetivação relações sociais mais humanas. Reconhecemos que as políticas públicas no Brasil sofrem com a preponderância das políticas econômicas sobre as políticas sociais, o que se configura como mais um desafio a ser vencido no enfrentamento à violência por meio de políticas públicas.

Entender as amarras econômicas, sociais, culturais, históricas que dificultam ações efetivas de combate à violência é importante para que não criemos ilusões de soluções fáceis para este grave problema contemporâneo. As condições perversas que historicamente vêm 
colocando crianças e jovens na condição de vítimas da violência por arma de fogo em níveis elevados no Brasil e no Espírito Santo fazem parte de uma herança deixada pela formação da sociedade brasileira marcada por conflitos e injustiças.

Por fim, tendo em vista que a conjuntura atual no Brasil revela diversas regressões e supressões de conquistas sociais anteriormente alcançadas, mostrando-se sombrio e preocupante, no que Boschetti (2017, p. 62) designa por “[...] tempos de agudização da barbárie [...]", o chamamento para a defesa intransigente dos direitos humanos deve ser forte e persistente.

\section{Referências}

BAPTISTA, M. V. Algumas reflexões sobre o sistema de garantia de direitos. Serviço Social \& Sociedade, v. 109, p. 179-199, 2012.

BOSCHETTI, I. Agudização da barbárie e desafios ao Serviço Social. Serviço Social \& Sociedade, São Paulo, n. 128, p. 54-71, jan./abr. 2017.

BRASIL. Lei no 8.069, de 13 de julho de 1990. Dispõe sobre o Estatuto da Criança e do Adolescente e dá outras providências. Brasília, 1990. Disponível em: www.planalto.gov.br/ccivil_03/Leis/I8069.htm. Acesso em: 17 jun. 2019.

BRASIL. Projeto de Lei 3.722, de 2012. Disciplina as normas sobre aquisição, posse, porte e circulação de armas de fogo e munições, cominando penalidades e dando providências correlatas. Brasília: Ministério da Justiça, Secretaria Nacional de Segurança Pública, 2012. Disponível em: https://www.defesa.org/pl-37222012/. Acesso em: 10 set. 2019

CADEMARTORI, A. N.; ROSO, A. Violência, criminalidade e relações de dominação: do Brasil colônia ao Brasil contemporâneo. Ser Social, Brasília, v. 14, n. 31, p. 397-418, jun./dez. 2012.

CALAZANS, R. G. S. R.; TRUGILHO, S. M.; SOGAME, L. C. M. Violência e juventudes: homicídios de jovens no Espírito Santo. Argumentum, Vitória, v. 12, n. 1, p. 82-101, jan./abr. 2020.

CARDOSO, F. Racismo e necropolítica: a lógica do genocídio de negros e negras no Brasil contemporâneo. Revista de Políticas Públicas, São Luís, v. 22, p. 949-968, 2018. (Número especial da VIII JOINPP)

CARVALHO, L. A.; ESPÍDULA, D. H. P. Discussões em torno do referendo sobre o comércio de armas de fogo e munição na Folha de S. Paulo. Opinião Pública. Campinas, v. 22, n. 2, p. 446465, agosto, 2016.

INSTITUTO DE PESQUISA ECONÔMICA APLICADA (IPEA). Atlas da Violência 2019. Brasília (DF), 2019. 
FARIA, A. A. C.; BARROS, V. A. Tráfico de drogas: uma opção entre escolhas escassas. Psicologia \& Sociedade, Florianópolis, v. 23, n. 3, p. 536-544, dez. 2011.

FIGUEIREDO, T. A. M.; COQUEIRO, J. M.; HERNANDES, L. F.; SOUZA, A. C. Crianças e adolescentes no contexto escolar: ações afirmativas contra o racismo. In: COQUEIRO J. M.; FIGUEIREDO, T. A. M. (Org.). Rizoma: Saúde Coletiva \& Instituições. 1. ed. Jundiaí: Paco Editora, v. 13, p. 157-172, 2017.

FONSECA, F. F. F.; SENA, R. K. R.; SANTOS, R. L.; DIAS, O. V. et al. As vulnerabilidades na infância e adolescência e as políticas públicas brasileiras de intervenção. Revista Paulistana de Pediatria, v. 31, n. 2, p. 258-64, 2013.

FONTENELLE, I. A. Ilusões de modernidade: o fetiche da marca McDonald's no Brasil. Psicologia \& Sociedade, v. 18, n. 2, p. 38-46, mai./ago. 2006.

FREIRE, S. M.; MURAD, L. C.; SILVA, L. T. S. Segurança pública, mídia e neoconservadorismo: a naturalização da barbarização das relações sociais. Revista de Políticas Públicas. São Luís, v. 23, n. 1, p. 212-231, 2019.

FREITAS, L. A. P. Adolescência, família e drogas. Rio de Janeiro: Mauad, 2002.

FREITAS, N. A. et al. Perfil clínico-epidemiológico de adolescentes e jovens vítimas de ferimento por arma de fogo. Cadernos Saúde Coletiva. Rio de Janeiro, v. 25, n. 4, p. 429-435, jan./out. 2017.

GENTILLI, R. M. L.; TRUGILHO, S. M. Violência e a Destrutividade da Sociedade do Capital: consequências para as políticas públicas. Revista de Políticas Públicas, São Luís, v. 18, n. 2, p. 523-534, jul./dez. 2014.

HERNANDES, L. F. Internação Compulsória: cenário político e vida em cena. 2016, $114 \mathrm{f}$. Dissertação (Mestrado em Políticas Públicas e Desenvolvimento Local) - Programa de PósGraduação Políticas Públicas e Desenvolvimento Local, Escola Superior de Ciências da Santa Casa de Misericórdia de Vitória - EMESCAM, Vitória, 2016.

INSTITUTO DE PESQUISA ECONÔMICA APLICADA (IPEA). Atlas da Violência 2018. Brasília, 2018.

LOPES. T. C.; COSTA, M. C. O.; MUSSE, J. O. Homicídios de crianças e adolescentes: Estudo dos registros do IML de Santana/Bahia. Revista Saúde Coletiva UEFS. Feira de Santana, v. 8, p. 16-22, 2018.

MACHADO, V. ES tem maior percentual de mortes por armas de fogo entre menores de 19 anos no Brasil, aponta Abrinq. G1 ES Online, dez. 2017. Disponível em: https://g1.globo.com/es/espirito-santo/noticia/es-tem-maior-percentual-de-mortes-porarmas-de-fogo-entre-menores-de-19-anos-no-brasil-aponta-abrinq.ghtml. Acesso em: 12 set. 2019. 
MINAYO, M. C. S. Violência e Saúde. Rio de Janeiro: Fiocruz, 2006. (Coleção Temas em Saúde)

MOURA, R. 0 perigoso fetiche pelas armas de fogo. 10 de junho de 2019. Disponível em: https://www.opovo.com.br/blogsecolunas/ricardomoura/2019/06/09/o-perigoso-fetichepelas-armas-de-fogo.html. Acesso em: 10 set. 2019.

NERY, L. Estatuto do Desarmamento. Jusbrasil, out. 2005. Disponível em: https://jus.com.br/artigos/7455/sim-estatuto-do-desarmamento. Acesso em: 14 set. 2019.

NETTO, J. P. Capitalismo e barbárie contemporânea. Argumentum. Vitória, v. 4, n. 1, p. 202222, jan./jun. 2012.

PORTELLA, D. D. A.; ARAUJO, E. M.; OLIVEIRA, N. F.; CHAVES, J. M.; ROCHA, W. J. S. F.; OLIVEIRA, D. D. Homicídios dolosos, tráfico de drogas e indicadores sociais em Salvador, Bahia, Brasil. Ciência \& Saúde Coletiva, v. 24, n. 2, p. 631-639, 2019.

RIBEIRO, A. P.; SOUZA, E. R.; SOUSA, C. A. M. Lesões provocadas por armas de fogo atendidas em serviços de urgência e emergência brasileiros. Ciência \& Saúde Coletiva. Rio de janeiro, v. 22, n. 9, jan./set. 2017.

SCHERER, G. A.; NUNES, C. F. Juvenicídio: descartabilidade da vida humana no Brasil contemporâneo. In: ENCONTRO INTERNACIONAL E NACIONAL DE POLÍTICA SOCIAL, 2018, Vitória. Anais eletrônicos do 60 Encontro Internacional de Política Social e 13 Encontro Nacional de Política Social, Vitória. Disponível em https://periodicos.ufes.br/einps/issue/view/862.

SILVA, J. F. S. Sociabilidades e violências: apontamentos críticos. In: Gentilli, R. M. L.; COELHO, M. C. R. (Orgs). Investigações sobre violência e sociabilidade: desafios transdisciplinares. São Paulo: Veras, p. 41-64, 2015.

SILVA, T. R. Musicalidade e Territórios da Pobreza: Juventude, periferia e manifestação popular através dos Raps de MV Bill. In: seminário nacional DE GESTÃO DE POLÍTICAS SOCIASI E TERRITÓRIO, 1, 2013, Londrina. Anais de Pesquisa do I Seminário Nacional de Gestão de Políticas Sociais e Território. Londrina: Universidade Estadual de Londrina, 2013.

SOUZA, C. A. Introdução Políticas Públicas: uma revisão da literatura. Sociologias. Porto Alegre, ano 8, n. 16, p. 20-45, jul./dez, 2006.

VALENZUELA, J. M. Juvenicidio: Ayotzinapa y las vidas precarias en América Latina y España. México: ITESO y El Colegio de la Frontera Norte, Biblioteca de la infancia y juventude, 2016.

WAISELFISZ, J. J. Mapa da violência 2016 homicídio por armas de fogo no Brasil. Brasília: OPAS/OMS, ONU Mulheres, SPM e Flacso, 2016. Disponível em: www.mapadaviolencia.org.br. Acesso em: 10 jul. 2019. 